\title{
Low-temperature heat capacities, thermophysical properties, optical spectra, and analysis of Schottky contributions to $\operatorname{Pr}(\mathrm{OH})_{3}{ }^{a}$
}

\author{
ROBERT D. CHIRICO, EDGAR F. WESTRUM, JR., \\ Department of Chemistry, University of Michigan, Ann Arbor, \\ Michigan 48109, U.S.A. \\ JOHN B. GRUBER, \\ Department of Physics, North Dakota State University, \\ Fargo, North Dakota 58102, U.S.A. \\ and JOYCE WARMKESSEL ${ }^{b}$ \\ Department of Chemistry, Arizona State University, \\ Tempe, Arizona 85281, U.S.A.
}

(Received 31 October 1978; in revised form 2 January 1979)

\begin{abstract}
From values of the heat capacity of microcrystalline $\operatorname{Pr}(\mathrm{OH})_{3}$ determined by precise adiabatic calorimetry from 15 to $350 \mathrm{~K}$, the Schottky contribution associated with all but the lowest Stark level was resolved with the aid of a model of the lattice heat capacity based upon the molar volumes of the lanthanide trihydroxides. Visible and infrared absorption spectra were taken at approximately $95 \mathrm{~K}$ on microcrystalline mulls and the energy-level scheme and crystalline electric-field parameters evaluated. The Schottky contribution of all levels above the first excited state $(\mu=3)$ was resolved by a new scheme for modeling the lattice contribution and compared with the same contribution deduced from the spectral results. Excellent accord was observed. These results together with magnetic results and the first excited Stark level were used to adjust the low-temperature heat capacities and thermodynamic functions so as to evaluate $C_{p} / R, S^{\circ} / R$, and $-\left\{G^{\circ}-H^{\circ}(0)\right\} / R T$, at $298.15 \mathrm{~K}$ as $14.154,15.84$, and 7.766 , respectively.
\end{abstract}

\section{Introduction}

The correlation of the electronic energy levels with heat capacities in lanthanide compounds has consistently posed problems in the resolution of the Schottky heat capacity contribution (arising from thermal population of low-lying Stark levels) from the often much larger vibrational ("lattice") contribution. Historically, the problem has been complicated by crystal structure changes along the series and by

${ }^{a}$ Supported in part by the Chemical Thermodynamics Program, Chemistry Division, National Science Foundation under contract no. CHE-77-10049.

${ }^{b}$ Present address: 767 Chopin Drive, Sunnyvale, California 94087, U.S.A. 
absence of adequate spectroscopic results. Thus, the heat capacity of the lanthanum analog has been used to represent the lattice heat capacities for nearby sesquioxides, ${ }^{(1)}$ for hexaborides, ${ }^{(2)}$ and for anhydrous trichlorides ${ }^{(3,4)}$ with resulting Schottky heat-capacity contributions above $20 \mathrm{~K}$ significantly lower than those deduced from spectral data. Even here, however, the authors noted that the lattice entropy $S^{\circ}$ (lattice), ${ }^{(4)}$ and lattice heat capacity at constant pressure $C_{p}$ (lattice) ${ }^{(5)}$, correlated best with the $\mathrm{Ln}^{3+}$ cation radius although its superiority to correlations involving other parameters was not great. Occasionally, portions of the heat capacities of other members of the series have been used to represent the lattice contribution. ${ }^{6,7)}$ Linear interpolations between the gadolinium and lutetium analogs on the basis of atomic number for the heavier C-type sesquioxides, ${ }^{(8,9)}$ and for the heavier trichloride hexahydrates, ${ }^{(10)}$ have also been done. With the exception of the ethyl sulfate nonahydrates $^{(6)}$ all of these series contain crystal-structure changes which preclude interpolation between the heat capacities of the (diamagnetic) end-members. The magnitudes of the total heat capacities of the lanthanide ethyl sulfate nonahydrates $\left(C_{p} / R \approx 40\right.$ at $\left.300 \mathrm{~K}\right)$ result in experimental uncertainties large in comparison with the Schottky contribution thus making the resolved Schottky and any spectroscopic corroboration equally uncertain.

Nearly all comparisons of Schottky contributions thus far made are confronted with a further complication, which arises because the optically determined energy levels are very often obtained for the paramagnetic ion of interest doped into a diamagnetic host lattice (commonly the La or $\mathrm{Y}$ analog) rather than for the concentrated salt. Wavenumber shifts of $20 \mathrm{~cm}^{-1}$ are not uncommon between these two systems. ${ }^{(11)}$

All the lanthanide trihydroxides have the same hexagonal crystal structure and have relatively small total heat capacities $\left(C_{p} / R \approx 13.5\right.$ at $\left.300 \mathrm{~K}\right)$. This, in conjunction with the fact that energy levels of five members of this series have been spectroscopically determined for the magnctically concentrated salts, makes the lanthanide trihydroxides an excellent series in which to study further trends in lattice heat capacities and the resolution of Schottky heat-capacity contributions.

In this initial paper we present the results of heat-capacity measurements on $\operatorname{Pr}(\mathrm{OH})_{3}$ from 15 to $350 \mathrm{~K}$. The lattice contribution was approximated by interpolating between the heat-capacities of $\mathrm{La}(\mathrm{OH})_{3}$ and $\mathrm{Gd}(\mathrm{OH})_{3}$ (corrected for co-operative magnetic ordering of the $\mathrm{Gd}^{3+}$ ions). When the interpolation is weighted by the fractional molar volume change calculated from the mean values of the known lattice parameters, corroboration of the calorimetrically deduced Schottky contribution, and hence the appropriateness of the lattice contribution for $\operatorname{Pr}(\mathrm{OH})_{3}$, is supplied by optical results on the magnetically concentrated salt.

Indeed, the optical spectra of tripositive praseodymium also has received considerable attention in recent decades. ${ }^{(11)}$ Studies covering the far infrared to the ultraviolet and cmbracing both crystal ${ }^{(11)}$ and vapor spectra ${ }^{(12-14)}$ have allowed experimentalists an excellent opportunity to identify the various levels associated with the $4 f^{2}$ sub-shell characteristic of $\mathrm{Pr}^{3+}$. Polarized absorption, fluorescence, and Zeeman spectra have been recorded for $\mathrm{Pr}^{3+}$ in single crystals of the lanthanide trihalides, ethyl sulfates, double nitrates, bromates, as well as in $\mathrm{CaF}_{2}, \mathrm{Y}_{2} \mathrm{O}_{3}$, and other diamagnetic optically transparent oxides. ${ }^{(15-20)}$ These spectra recorded between 1.4 and $300 \mathrm{~K}$ have provided 
considerable detail on the crystalline clectric-field (CEF) splitting of the $4 \mathrm{f}^{2}[S L] J$ manifolds which in turn has prompted theorists to examine the atomic structure in considerable depth beyond the usual Hartree-Fock approximations. ${ }^{(21,22)}$

In vogue for some years have been the so-called "free-ion model, in which the free-ion (Racah) parameters are evaluated by making use of the experimental centers of gravity of the CEF-split $4 \mathrm{f}^{n}[S L] J$-manifolds. ${ }^{(21)}$ The CEF parameters are then established using perturbation theory or by completely diagonalizing the crystal-field matrices. ${ }^{(11)}$ In numerous instances for diverse rare-earth spectra these approaches have been satisfactory. However, in the presence of numerous $J$-manifolds and lowlying excited configurations, these methods lead to considerable difficulty, for they ignore such effects as two-body magnetic interactions, shifts in centers of gravity due to configuration interaction, and crystal-field shielding or screening by electrons with regard to the surrounding electric fields in the lattice. ${ }^{(23-25)}$

Configuration-interaction processes give rise to effects that cannot be included in the conventional "one-electron" crystal-field parameters $\left(A_{n}^{m}<r^{n}>\right.$ or later $\left.B_{n m}\right)$ originally defined and normalized by Stevens, ${ }^{(26)}$ by Elliott, ${ }^{\left({ }^{27)}\right.}$ and by Judd. ${ }^{(28)}$ In fact these CEF parameters show an apparent term-dependence when efforts were made to fit observed optical spectra of different spin multiplicities of the same ion with earlier CEF calculation. ${ }^{(29)}$ These observations are consistent with earlier theoretical work on configuration interaction by Rajnak and Wybourne ${ }^{(30)}$ in 1964. More recently correlation crystal fields for $n^{\prime} \mathrm{f}^{n}$ systems have been investigated by Judd. ${ }^{(31,32)}$ Also Newman ${ }^{(33)}$ has proposed a parametrization of crystal-induced correlation between f-electrons that will give experimentalists an opportunity to re-examine the interpretation of earlier and current optical data.

More than any other lanthanide ion $\mathrm{Pr}^{3+}$ has received considerable in depth theoretical assessment beginning with the application of perturbation theory to CEF splitting by Judd ${ }^{(34)}$ and followed by successive developments by Margolis, ${ }^{(35)}$ by Rajnak and Wybourne, ${ }^{(36)}$ by Wong, ${ }^{(37)}$ by Wybourne, ${ }^{(38)}$ by Judd, Crosswhite, and Crosswhite, ${ }^{(39)}$ by Bishton and Newman, ${ }^{(23)}$ and by Morrison, Fields, and Carnall. ${ }^{(24)}$ Recent work by Judd ${ }^{(31,32)}$ and by Newman ${ }^{(33)}$ points out the importance of the correlation crystal field by suggesting models to improve the CEF splitting of the singlet states, particularly ${ }^{1} \mathrm{D}_{2}$ relative to the successful fits of CEF parameters to the triplet states, ${ }^{3} \mathrm{P}_{j},{ }^{3} \mathrm{~F}_{j}$, and ${ }^{3} \mathrm{H}_{j}$.

Optical and magnetic studies of the lanthanide hydroxides have appeared rather late in comparison with similar studies on other lanthanide compounds. ${ }^{(40-44)}$ The difficulty in growing hydroxide crystals probably led earlier experimentalists to favor such lattices as the trichlorides and ethyl sulfates for example, for which large select single crystals can be grown rather easily. ${ }^{(1)}$ Yet optical spectra, CEF splittings, and analyses have been reported for the hydroxides of $\mathrm{Eu}^{3+}, \mathrm{Gd}^{3+}, \mathrm{Tb}^{3+}, \mathrm{Dy}^{3+}$, and $\mathrm{Er}^{3+}$ as well as for $\mathrm{Gd}^{3+}, \mathrm{Tb}^{3+}, \mathrm{Ho}^{3+}$, and $\mathrm{Er}^{3+}$ diluted into $\mathrm{Y}(\mathrm{OH})_{3}$. CEF calculations involving perturbation theory and including $J-J$ mixing, gave results in general agreement with experimental energy levels within 2 to 4 per cent error. ${ }^{(40-43,45)}$ To our knowledge the spectra and CEF calculations for $\operatorname{Pr}(\mathrm{OH})_{3}$ have not yet been reported.

The present paper is then a presentation of both the thermophysical results and the 
spectral results for praseodymium trihydroxide and the interpretation and rcconciliation of the Schottky contributions derived from both.

\section{Experimental}

\section{PREPARATION AND CHARACTERIZATION OF THE Pr(OH $)_{3}$ SAMPLES}

Sample for optical measurements. Preparation of $\operatorname{Pr}(\mathrm{OH})_{3}$ samples as well as recording of the absorption spectra were carried out in 1967 in the Chemistry Department of Arizona State University by one of the authors (JW) who at that time was a graduate student of Professor LeRoy Eyring. Interest in the hydroxide spectra came originally from the observation of $\operatorname{Pr}(\mathrm{OH})_{3}$ absorption peaks in the spectra of nonstoichiometric praseodymium oxides. ${ }^{(46)}$

$\operatorname{Pr}(\mathrm{OH})_{3}$ was prepared by exposing the A-form sesquioxide to air for many weeks. After this length of time the X-ray diffraction pattern of these samples revealed only lines belonging to the hydroxide. $\left(\operatorname{Pr}(\mathrm{OH})_{3}\right.$ prepared directly by precipitation from solution is amorphous and becomes crystalline only after standing for long periods; ${ }^{(46-48)}$ the latter form is necessary for obtaining the detailed structure in the absorption spectrum associated with the CEF splitting of the excited [SL] $J$-manifolds.)

Mulls of finely divided crystalline $\operatorname{Pr}(\mathrm{OH})_{3}$ were prepared with Kel-F No. 90 grease as a matrix. Quite stiff mulls which still flowed when pressed between a quartz plate and the sample holder gave best results. To improve thermal contact between the mull and the copper block of the optical-conduction dewar, a mesh made from $0.122 \mathrm{~mm}$ diameter copper wire was soldered on to the sides of the copper block and thermally attached to the quartz plate of the sample holder. This technique of applying the mull over the wire mesh brought the mull temperature closer to that of the block.

Sample for thermophysical measurements. Praseodymium sesquioxide was prepared by reduction of $\mathrm{Pr}_{6} \mathrm{O}_{11}$ (99.99 moles per cent pure, Research Chemicals, Phoenix. Arizona) in a stream of hydrogen at about $1170 \mathrm{~K}$. The sesquioxide was synthesized only as nccded to minimize possible $\mathrm{CO}_{2}$ contamination. The pale-green product was then transferred into gold tubes for direct reaction with water at $170 \mathrm{MPa}$ and $(840 \pm 25) \mathrm{K}$ for $40 \mathrm{~h}$ using the hydrothermal technique previously described by Haschke and Eyring. ${ }^{(4)}$ The gold tubes were crimped with a three-jawed chuck to allow direct communication between the pressurized water in the reactor and the sesquioxide. Powder X-ray diffraction results using a $114.6 \mathrm{~mm}$ Hägg-type Guinier camera $\left(\mathrm{CuK} \alpha_{1}\right.$ radiation, $\left.\lambda=0.15405 \mathrm{~nm}\right)$ with silicon $(a=0.543062 \mathrm{~nm})$ as an internal standard showed only the presence of the hexagonal $\mathrm{UCl}_{3}$-type structure with lattice parameters in excellent agreement with those previously reported in the literature. ${ }^{(48-50)}$ The stoichiometry was determined to be $\operatorname{Pr}(\mathrm{OH})_{(3.000 \pm 0.003)}$ by direct ignition of samples to (black) $\operatorname{Pr}_{6} \mathrm{O}_{11}$.

\section{OPTICAL SPECTRAL MEASUREMENTS}

Absorption spectra were recorded using an optical-conduction dewar mounted in the sample chamber of a Cary 14 spectrophotometer. With liquid nitrogen as coolant and differential thermocouples to measure the temperature of the mull, results in the visible region of the spectrum were recorded at $95 \mathrm{~K}$. Although the mull temperature 
remained reasonably constant when the visible source of the spectrometer was on, it increased slightly when infrared excitation was being used because of radiation from the blackbody source.

Results were obtained in the visible and near infrared regions (440 to $1500 \mathrm{~nm}$ ). The resolving power of the monochromator in the Cary 44 was about $0.1 \mathrm{~nm}$ in the ultraviolet and visible regions and about $0.3 \mathrm{~nm}$ in the near infrared. Reproducibility of the wavelength scale was $0.05 \mathrm{~nm}$ and the instrument was calibrated by the manufacturer to within $0.2 \mathrm{~nm}$ over the wavelengths scanned.

The observed mull spectra are not as sharp and detailed as one might expect from a large single crystal of $\operatorname{Pr}(\mathrm{OH})_{3}$. Moreover, the random orientation of the many small crystals in the mull precludes the opportunity of taking the polarized absorption spectra as a means of identifying the quantum labels associated with excited Stark components of each $[S L] J$-manifold. Finally, the lack of spectra taken using liquid helium as a coolant removes one of the techniques used to identify temperature-dependent transitions from the Stark components of the ground-state manifold ${ }^{3} \mathrm{H}_{4}$.

The absorption spectrum of the mull is sufficiently resolved so that many of the Stark components of excited manifolds can be established energetically even if quantum assignments cannot be made. However, since the $\mathrm{Pr}^{3+}$ ion has the same point-group symmetry, $C_{3 h}$, in the hydroxide lattice as that in the trichloride and the tribromide lattices and since the CEF splitting shows similarity to the latter spectra, it is reasonable to make a tentative assignment based on these similarities. Moreover, to the low-energy side of the relatively strong zero-phonon transitions assigned as coming from the ground-state Stark level, more than 24 weaker transitions, which repeat energy level differences between excited manifolds occur. This strongly suggests that they are temperature-dependent transitions from excited Stark components of the ground-state ${ }^{3} \mathrm{H}_{4}$ manifold. If it is assumed that strong transitions involve the ground Stark-level, the relative intensity of the transitions identified as temperature dependent can be calculated by using the Boltzmann equation for population distributions. This has been done with good success and reinforces the experimental assignments given to the ${ }^{3} \mathrm{H}_{4}$ Stark components.

The energy-level scheme reported in table 1 is consistent with the $C_{3 h}$ selection rules for electric-dipole transitions. Where selection rules forbid transitions, none appears in the present assignments. Choice of zero-phonon transition assignments was aided also by analysis of the vibronic side-bands which appear partly resolved and which have been successfully identified in both the $\mathrm{Pr}^{3+}$ and $\mathrm{Nd}^{3+}$ ions in the trihalide and ethyl-sulfate lattices. ${ }^{(52-53)}$

The CEF splitting for manifolds ${ }^{3} \mathrm{P}_{2},{ }^{3} \mathrm{P}_{1},{ }^{1} \mathrm{D}_{2},{ }^{3} \mathrm{Z}_{3},{ }^{3} \mathrm{~F}_{4},{ }^{1} \mathrm{G}_{4}$, and ${ }^{3} \mathrm{H}_{4}$ are presented in table 1. Assigned crystal quantum states $(\mu)$ are taken from CEF calculations reported later in this paper and are based on $B_{n m}$ parameters which are quite reasonable in comparison with those reported for $\mathrm{Eu}^{3+}, \mathrm{Gd}^{3+}, \mathrm{Tb}^{3+}, \mathrm{Dy}^{3+}, \mathrm{Ho}^{3+}$, and $\mathrm{Er}^{3+}$ in hydroxide lattices. ${ }^{(42)}$ Configuration interaction, especially noted upon ${ }^{1} \mathrm{D}_{2}$, needs to be examined in light of recent work by Judd ${ }^{(31,32)}$ and by Newman ${ }^{(33)}$ and is discussed later under CEF calculations. The ${ }^{3} \mathrm{P}_{1}$ and ${ }^{1} \mathrm{I}_{6}$ levels are found to overlap, making the experimental assignments somewhat difficult, but not impossible, to establish. The overall $[S L] J$-manifold splitting is larger than that found in either the 
840 R. D. CHIRICO, E. F. WESTRUM, JR., J. B. GRUBER, AND J. WARMKESSEL

TABLE 1. Energy Levels of $\operatorname{Pr}^{3+}\left(4 f^{2}\right)$ in $\operatorname{Pr}(\mathrm{OH})_{3}$

\begin{tabular}{|c|c|c|c|c|c|c|c|}
\hline $\begin{array}{l}\text { State } \\
{[S L] J}\end{array}$ & $\begin{array}{c}\mu^{a} \\
\text { (assigned) }\end{array}$ & $\begin{array}{c}\tilde{v} / \mathrm{cm}^{-1} \\
\text { (obs) }\end{array}$ & $\begin{array}{c}\tilde{v} / \mathrm{cm}^{\circ} \\
(\mathrm{calc}, \mathrm{I})\end{array}$ & $\begin{array}{l}\Delta \tilde{v} / \mathrm{cm}^{-1} \\
\text { (I) }\end{array}$ & $\begin{array}{l}\tilde{v} / \mathrm{cm}^{-1 \mathrm{c}} \\
\text { (calc, II) }\end{array}$ & $\begin{array}{l}\Delta \tilde{v} / \mathrm{cm}^{-1} \\
\text { (II) }\end{array}$ & $\mu, \Delta \tilde{v} / \mathrm{cm}^{-1 d}$ \\
\hline \multirow{3}{*}{${ }^{\mathrm{a}} \mathbf{P}_{2}$} & \pm 2 & 22481 & 22474 & -7 & 22479 & -2 & $\pm 2(120), \pm 1(270), 0(380)$ \\
\hline & \pm 1 & 22340 & 22342 & +2 & 22340 & 0 & $3(11), \pm 2(270)$ \\
\hline & 0 & 22261 & 22265 & +4 & 22262 & +1 & $3(12), \pm 2(120), 3(175)$ \\
\hline \multirow{2}{*}{${ }^{3} \mathbf{P}_{1}$} & 0 & 21292 & 21290 & -2 & 21292 & 0 & $3(12), \pm 2(120)$ \\
\hline & \pm 1 & 21147 & 21148 & +1 & 21147 & 0 & $3(13)- \pm 2(122)$ \\
\hline${ }^{3} \mathrm{P}_{0}$ & 0 & 20501 & - & - & 20502 & +1 & $3(10), \pm 2(120), 3(175)$ \\
\hline \multirow[t]{3}{*}{${ }^{1} \mathbf{D}_{2}$} & \pm 2 & 17174 & 17144 & -30 & 17148 & -16 & $\pm 2(119), \pm 1(271), 0(380)$ \\
\hline & \pm 1 & 17098 & 17094 & -4 & 17096 & -2 & $\pm 2(120), \pm 1(270)$ \\
\hline & 0 & 16825 & 16851 & +26 & 16833 & +8 & $3(11), \pm 2(120)$ \\
\hline \multirow{6}{*}{${ }^{1} \mathrm{G}_{4}$} & \pm 2 & 9964 & 9966 & +2 & 9965 & 1 & $\pm 2(116), \pm 1(270)$ \\
\hline & \pm 1 & 9848 & 9846 & -2 & 9484 & 0 & $3(10)$ \\
\hline & 0 & 0778 & 9773 & -5 & 9774 & -4 & $\pm 2(120)$ \\
\hline & \pm 2 & 9778 & 9772 & -6 & 9777 & -1 & $3(176)$ \\
\hline & 3 & - & 9720 & - & 9722 & - & \\
\hline & 3 & - & 9464 & - & 9448 & - & \\
\hline \multirow{6}{*}{${ }^{3} F_{4}$} & \pm 2 & 7035 & 7030 & -5 & 7033 & -2 & $\pm 2(121)$ \\
\hline & 0 & $(6985)$ & 6975 & -10 & 6981 & -4 & \\
\hline & +1 & & 6974 & -11 & 6985 & 0 & $\pm 2(120), 3(175)$ \\
\hline & \pm 2 & 6935 & 6945 & +10 & 6940 & +5 & $\pm 2(119)$ \\
\hline & 3 & - & 6919 & - & 6916 & - & $\pm 2(119)$ \\
\hline & 3 & 6865 & 6877 & +12 & 6868 & +3 & $\pm 1(270), 0(380)$ \\
\hline \multirow[t]{6}{*}{${ }^{3} \mathrm{H}_{4}$} & 0 & 380 & 385 & +5 & 383 & +3 & \\
\hline & \pm 1 & 270 & 262 & -8 & 268 & -2 & \\
\hline & 3 & 175 & 171 & -4 & 175 & 0 & \\
\hline & \pm 2 & 120 & 120 & 0 & 119 & $\cdots 1$ & \\
\hline & 3 & $11 \pm 2$ & 13 & +2 & 11 & 0 & \\
\hline & \pm 2 & 0 & 0 & 0 & 0 & 0 & \\
\hline
\end{tabular}

* Assigned crystalline electric-field quantum numbers.

${ }^{b}$ These are the results of a first-order CEF calculation described in the text. The following column indicates the difference (calc, $\mathrm{I}$ ) - (obs).

c This CEF calculation based upon the complete diagonalization of the coulombic spin-orbit and crystalline-field matrices as described in the text. The following column indicates the difference: (calc, II) - (obs).

${ }^{d}$ The numbers in parentheses represent observed energy differences. In front of each energy difference is the assigned $\mu$ from the ground state ${ }^{3} \mathrm{H}_{4}$. The $\mu=(11 \pm 2) \mathrm{cm}^{-1}$ Stark level is observed as a shoulder on the peak assigned as coming from the ground state $\mu= \pm 2$. Since the spectrum cannot be fully resolved, it is possible that this predicted level could lie lower than $11 \mathrm{~cm}^{-1}$. Unpublished spectra ${ }^{(51)}$ with the sample immersed in liquid helium indicate that the level could be as little as $8 \mathrm{~cm}^{-1}$ above the ground Stark level.

trichloride or the ethyl-sulfate lattices. ${ }^{(15,48)}$ This is not surprising since the lattice constants for $\operatorname{Pr}(\mathrm{OH})_{3}$ are smaller $(c=0.377 \mathrm{~nm}, c / a=0.582)$ than those for either $\mathrm{PrCl}_{3}(c=0.4275 \mathrm{~nm}, c / a=0.576)$ or for the ethyl sulfate $(c=0.709 \mathrm{~nm}$, $c / a=0.506){ }^{(44)}$ Even with this larger splitting, the experimental centers of gravity of excited manifolds, when reduced by subtracting the center of gravity of ${ }^{3} \mathrm{H}_{4}$, show only a small shift to higher energy relative to what has been observed in the trihalide and ethyl-sulfate spectra. ${ }^{(11)}$ 


\section{THERMOPHYSICAL MEASUREMENTS}

Calorimeter and cryostat A $108.356 \mathrm{~g}$ sample of the previously described $\operatorname{Pr}(\mathrm{OH})_{3}$ was loaded into the gold-plated copper calorimeter (laboratory designation W-54) provided with a screw-type closure involving a stainless-steel knife edge and an annealed gold gasket. The loaded calorimeter was evacuated and after the addition of $1.50 \mathrm{kPa}$ at $300 \mathrm{~K}$ of purified helium to facilitate thermal equilibration, the calorimeter was sealed. A small amount of Apiezon-T grease of known mass was placed in the thermocouple and heater-thermometer wells of the calorimeter to provide good thermal contact between the heater, the temperature sensors, and the calorimeter.

Calorimetric technique Heat-capacity measurements were made in the range 5 to $350 \mathrm{~K}$ in the Mark II adiabatic cryostat. ${ }^{(54)}$ A Leeds and Northrup capsule-type platinumresistance thermometer (laboratory designation A-5) was used for temperature and temperature-increment determinations. The thermometer was calibrated at the U.S. National Bureau of Standards (N.B.S.) against the IPTS-1948 (as textually revised in $1960)^{(55)}$ for temperatures above $90.2 \mathrm{~K}$, against the N.B.S. provisional scale from 10 to $90 \mathrm{~K}$, and by the calibration technique of McCrackin and Chang ${ }^{(56)}$ below $10 \mathrm{~K}$. These calibrations are judged to reproduce thermodynamic temperatures to within $0.03 \mathrm{~K}$ from 10 to $90 \mathrm{~K}$ and to within $0.04 \mathrm{~K}$ above $90 \mathrm{~K}$. Determination of mass, current, potential, and time are based upon calibrations performed at the N.B.S. The accuracy of a single heat-capacity measurement is judged to be about 0.2 per cent at $15 \mathrm{~K}$ decreasing to about 0.1 per cent at $25 \mathrm{~K}$ and to about 0.06 per cent between 25 and $350 \mathrm{~K}$ even though precision is significantly better at low temperatures.

\section{Results and discussion}

\section{CRYSTAL-FIELD SPLITTING CALCULATIONS}

The CEF calculations first performed were made using intermediate coupling and included the $J$-mixing effects of the crystal field. ${ }^{(11,21)}$ Intermediate coupling wave functions and reduced matrix elements were generated using Racah parameters: $E^{1}=4868.9 \mathrm{~cm}^{-1}, \quad E^{2}=22.821 \mathrm{~cm}^{-1}, \quad E^{3}=483.6 \mathrm{~cm}^{-1}, \quad \zeta=761.3 \mathrm{~cm}^{-1}$, $\alpha=34.421 \mathrm{~cm}^{-1}, \beta=-600.2 \mathrm{~cm}^{-1}$, and $\gamma=728 \mathrm{~cm}^{-1}$. These parameters, based on the "free-ion energies", were obtained by subtracting the center of gravity of the ${ }^{3} \mathrm{H}_{4}$ manifold from the experimental center of gravity of each excited $[S L] J$-manifold.

The Hamiltonian for $\operatorname{Pr}^{3+}\left(4 \mathrm{f}^{2}\right)$ at a site of $C_{3 h}$ symmetry is given as:

$$
H=H_{0}+\left(B_{20} V_{2}^{0}+B_{40} V_{4}^{0}+B_{60} V_{6}^{0}+B_{66} V_{6}^{6}\right) \text {, }
$$

in which $H_{0}$ is the free-ion Hamiltonian and the remaining terms describe the effect of the crystalline environment. The crystal-field parameters, $\mathbf{B}_{20}, \mathbf{B}_{40}, \mathbf{B}_{60}$, and $\mathbf{B}_{66}$, have been defined and normalized according to the procedurcs of Stcvens, ${ }^{(26)}$ of Elliot and Stevens, ${ }^{(27)}$ and of Judd. ${ }^{(28)}$ A first-order perturbation calculation was made using the ${ }^{3} \mathrm{P}_{j},{ }^{3} \mathrm{~F}_{j}$, and ${ }^{3} \mathrm{H}_{4}$ levels to ascertain a set of four CEF parameters to be used in a program (a) that diagonalized the four crystal-field matrices (Stark levels of $\mu_{+2}$, $\left.\mu_{+1}, \mu_{0}, \mu_{3}\right)$ together with the free-ion Hamiltonian, and (b) which fitted the eigenvalues to the experimental levels reported in table 1 . By allowing all parameters to vary simultaneously, the free-ion parameters changed in value in such a way as to minimize 
the effect of the crystal field, while larger CEF parameters were then generated to fit the observed Stark levels. The computer program was constructed by combining earlier programs for free-ion energy levels including partial effects from configuration interaction received from John Conway (Lawrence Radiation Laboratory, Berkeley) and CEF programs originally received from Paul Meijer (Catholic University, Washington, D.C.). New Racah parameters thus generated included $E^{1}=4865.7 \mathrm{~cm}^{-1}$, $E^{2}=22.782 \mathrm{~cm}^{-1}, \quad E^{3}=475.2 \mathrm{~cm}^{-1}, \quad \zeta=759.6 \mathrm{~cm}^{-1}, \quad \alpha=23.292 \mathrm{~cm}^{-1}$, $\beta=-607.3 \mathrm{~cm}^{-1}$, and $\gamma=735 \mathrm{~cm}^{-1}$. Both the first-order CEF parameters and those obtained by complete diagonalization are found in table 2 and identified by I and II, respectively. Uncertainties in the Racah parameters as well as in the CEF parameters are comparable to those reported earlier. ${ }^{(24,39,52)}$

TABLE 2. CEF parameters for $\operatorname{Pr}(\mathrm{OH})_{3}$

\begin{tabular}{lcccc}
\hline & $B_{20} / \mathrm{cm}^{-1}$ & $B_{40} / \mathrm{cm}^{-1}$ & $B_{60} / \mathrm{cm}^{-1}$ & $B_{66} / \mathrm{cm}^{-1}$ \\
\hline & $237 \pm 5$ & $-85 \pm 3$ & $-52 \pm 2$ & $590 \pm 20$ \\
First order (I) & $240 \pm 2$ & $-88 \pm 2$ & $-53 \pm 2$ & $630 \pm 10$ \\
\hline
\end{tabular}

The calculations presented so far have not included two-particle correlation induced by the environment as discussed by Bishton and Newman, ${ }^{(23)}$ nor the effective operators introduced by Rajnak and Wybourne, ${ }^{(36)}$ by Wybourne, ${ }^{(38)}$ and by Armstrong, ${ }^{(57)}$ which take into account the perturbing effects of all higher-lying configurations to second-order in perturbation theory. Morrison et al. ${ }^{(24)}$ considered a phenomenological scheme based on the assumption that second-order perturbation terms involving electrostatically induced configuration interaction of the $4 \mathrm{f}^{n}$ shell with $n \mathrm{p}$ and $n \mathrm{f}$ shells provide the dominant contribution to the correlation crystal field. Newman ${ }^{(33)}$ has rejected this approach as unduly restrictive and has recently proposed a scheme to reduce the number of correlation parameters required in addition to the familiar "one-electron" CEF parameters. Newman ${ }^{(33)}$ has suggested two possible approaches to understanding correlation crystal fields: one (1) is based on the supposed dominance of ligand polarization contributions and the other (2) is based on assumed dominance of configuration interaction contributions. Levels of approximation are possible for either assumption so that parametrization can be chosen to suit a given set of experimental results. At the present time, lacking the spectra of $\operatorname{Pr}^{3+}$ diluted in $\mathrm{Y}(\mathrm{OH})_{3}$, the authors feel that, with the exception of the ${ }^{1} \mathrm{D}_{2}$ level, the present calculated values given in table 1 using "one-electron" CEF parameters normalized following Stevens, ${ }^{(26)}$ Elliott and Stevens, ${ }^{(27)}$ and $\mathrm{Judd}^{(28)}$ are in reasonable agreement (better than 4 per cent) with the reported energy-level scheme for $\operatorname{Pr}(\mathrm{OH})_{3}$ which is also given in table 1 . Without a detailed CEF analysis of additional levels such as ${ }^{1} \mathbf{I}_{6}$, ${ }^{3} \mathrm{~F}_{2},{ }^{3} \mathrm{H}_{6}$, and ${ }^{3} \mathrm{H}_{5}$, the authors do not have sufficient Stark levels to test Newman $\mathrm{s}$ approach that involves a considerable increase in parameters depending on the level of approximation. Moreover, the determined CEF parameters appear to explain the Schottky heat-capacity contribution reported later in this paper. 


\section{HEAT CAPACITIES AND THERMOPHYSICAL FUNCTIONS $\dagger$}

The heat capacity of $\operatorname{Pr}(\mathrm{OH})_{3}$ may be represented by a simple sigmate curve from 15 to $350 \mathrm{~K}$. Below $15 \mathrm{~K}$ thermal equilibration was much too slow to allow proper maintenance of adiabatic conditions. The problem was definitely related to the crystalline size and may have been due to absorption of the helium exchange gas by the sample. Eater measurements made on a sample of $\mathrm{Tb}(\mathrm{OH})_{3}$ with larger crystals encountered no such problems at temperatures as low as $4.5 \mathrm{~K}$.

The experimental heat capacities were processed by subtraction of the heat capacity due to the empty calorimeter (determined separately) and corrected for small differences in the amounts of helium gas, $(\mathrm{Pb}+\mathrm{Sn})$ solder, and stainless steel relative to the calorimeter when run empty. The calorimeter and heater-thermomcter assembly represented 20 to 40 per cent of the total measured heat capacity. Curvature corrections were applied to obtain true heat capacities (i.e. $\lim _{\Delta T \rightarrow 0}(\Delta H / T)=C_{p}$ ) from the measured $\Delta H / \Delta T$ values.

TABLE 3. Experimental vaiues of the heat capacity of $\operatorname{Pr}(\mathrm{OH})_{3}$

\begin{tabular}{|c|c|c|c|c|c|c|c|}
\hline$T / \mathbf{K}$ & $C_{p} / R$ & $T / \mathrm{K}$ & $C_{p} / R$ & $T / \mathbf{K}$ & $C_{p} / R$ & $T / \mathrm{K}$ & $C_{p} / R$ \\
\hline \multicolumn{2}{|c|}{ Series 1} & 159.13 & 9.594 & \multicolumn{2}{|c|}{ Series 6} & 15.35 & 0.329 \\
\hline 66.41 & 3.407 & 167.93 & 10.019 & 267.46 & 13.447 & 16.92 & 0.346 \\
\hline 70.30 & 3.714 & 176.86 & 10.417 & 277.27 & 13.681 & 18.49 & 0.370 \\
\hline 75.62 & 4.139 & 185.94 & 10.802 & 287.09 & 13.910 & 20.17 & 0.406 \\
\hline 81.88 & 4.648 & 195.08 & 11.175 & & & 21.97 & 0.456 \\
\hline \multirow[t]{2}{*}{89.02} & \multirow[t]{2}{*}{5.213} & \multirow{2}{*}{\multicolumn{2}{|c|}{ Series 4}} & \multirow{2}{*}{\multicolumn{2}{|c|}{ Series 7}} & 23.95 & 0.523 \\
\hline & & & & & & 26.12 & 0.610 \\
\hline \multicolumn{2}{|c|}{ Series 2} & 201.57 & 11.424 & 297.12 & 14.135 & 28.48 & 0.717 \\
\hline 85.27 & 4.921 & 211.04 & 11.766 & 306.44 & 14.331 & 31.02 & 0.847 \\
\hline 92.65 & 5.479 & 220.53 & 12.093 & 315.40 & 14.532 & 33.16 & 0.966 \\
\hline 100.26 & 6.024 & \multirow{2}{*}{\multicolumn{2}{|c|}{ Series 5}} & 324.41 & 14.683 & 36.42 & 1.163 \\
\hline 108.00 & 6.559 & & & 333.51 & 14.849 & 40.02 & 1.396 \\
\hline \multirow[t]{2}{*}{116.95} & 7.165 & 215.30 & 11.920 & 341.85 & 15.011 & 44.01 & 1.671 \\
\hline & & 224.59 & 12.225 & 347.95 & 15.103 & 48.46 & 1.997 \\
\hline \multicolumn{2}{|c|}{ Series 3} & 233.98 & 12.523 & & & 53.14 & 2.350 \\
\hline 123.53 & 7.597 & 243.51 & 12.797 & \multicolumn{2}{|c|}{ Series 8} & 58.17 & 2.742 \\
\hline 132.21 & 8.123 & 253.06 & 13.077 & 9.86 & 0.326 & 63.90 & 3.203 \\
\hline 141.06 & 8.634 & 262.63 & 13.331 & 11.47 & 0.323 & 70.10 & 3.698 \\
\hline 150.09 & 9.127 & 272.32 & 13.581 & 13.52 & 0.318 & & \\
\hline
\end{tabular}

The heat capacities (based on a molar mass of $191.929 \mathrm{~g} \mathrm{~mol}^{-1}$ ) are listed for $\operatorname{Pr}(\mathrm{OH})_{3}$ in chronological sequence in table 3 so that the $\Delta T^{\prime}$ 's employed usually can be estimated from the adjacent mean-temperatures. These results (depicted in figure 1) were fitted to a power series in orthogonal polynomials in reduced temperature as described by Justice. ${ }^{(58)}$ The thermodynamic functions in table 4 were derived through appropriate integration of the fitted polynomial. These functions do not include contributions from nuclear spin and isotope mixing and are thus suitable for use in ordinary thermochemical calculations.

In 1977 Folinsbee et al. ${ }^{(44)}$ expressed the intention to measure the heat capacity of $\operatorname{Pr}(\mathrm{OH})_{3}$ to temperatures below $1.25 \mathrm{~K}$. These results are not yet available; therefore,

$\uparrow$ Throughout this paper a value of $R=8.31441 \mathrm{~J} \mathrm{~K}^{-1} \mathrm{~mol}^{-1}$ has been used. 


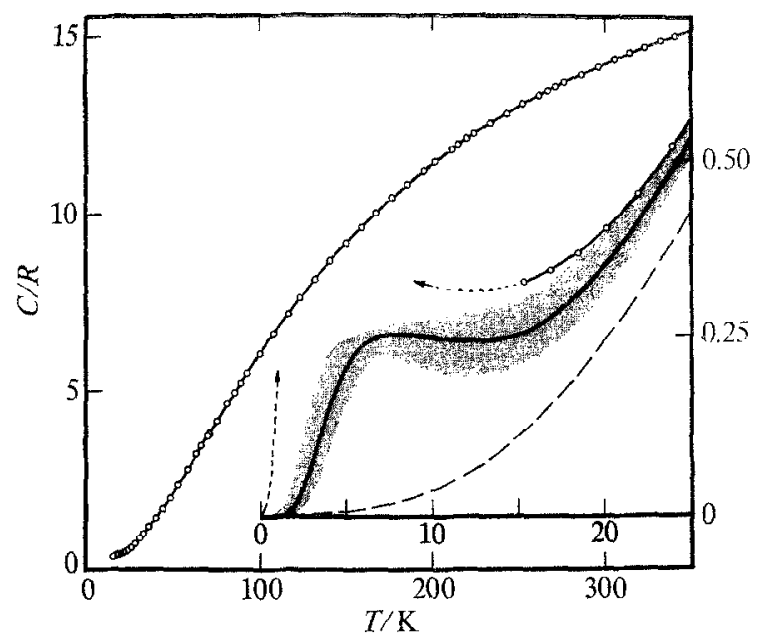

FIGURE 1. The low-temperature heat capacity of $\operatorname{Pr}(\mathrm{OH})_{3}$. The open circles represent experimental results of this research. The short-dashed lines on the very low-temperature insert indicate the calculated antiferromagnetic anomaly and the long-dashed lines the lattice contribution. The continuous line represents the Schottky contribution (plus the lattice contribution) derived from the heat-capacity results shown. The shaded areas delineate the reliability of the spectroscopic results i.e. the Schottky contribution deduced from the energy levels with an uncertainty of $\pm 3 \mathrm{~cm}^{-1}$.

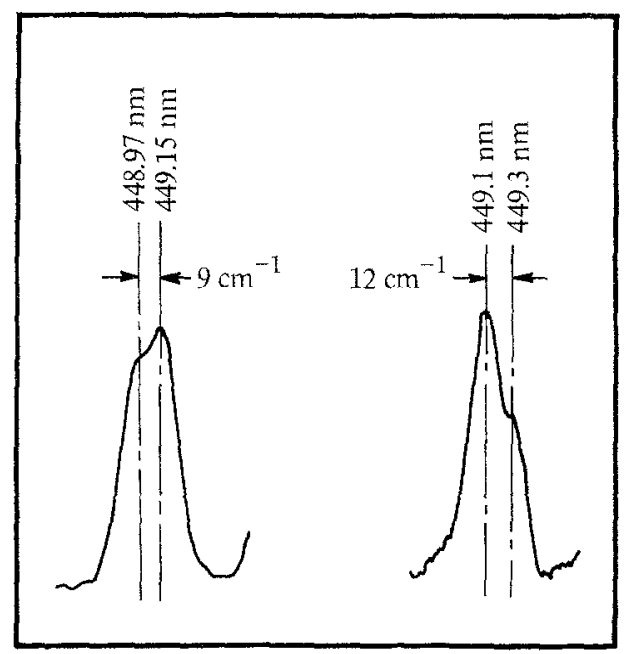

FIGURE 2. Electronic transitions from ${ }^{3} \mathrm{H}_{4}, \mu( \pm 2)=0$ and $\mu(3)=(11 \pm 2) \mathrm{cm}^{-1}$ (see table 1), to the excited state ${ }^{3} \mathrm{P}_{2}, \mu(0)=22261 \mathrm{~cm}^{-1}$. At $4.2 \mathrm{~K}$ (see left-hand figure) there is relatively strong phonon interaction between the ground and first excited Stark levels. At $90 \mathrm{~K}$ the resolution of these same levels is somewhat better (see right-hand figure). The spectra appear to shift to the red with evidence for a relative shift between transitions as well. The shifts are occasioned by thermal expansion of the lattice between 4 and $90 \mathrm{~K}$ (see reference 51.) 
TABLE 4. Thermodynamic properties of $\operatorname{Pr}(\mathrm{OH})_{3}$

\begin{tabular}{|c|c|c|c|c|}
\hline$\frac{T}{\mathrm{~K}}$ & $\frac{C_{p}}{R}$ & $\frac{S^{\circ}(T)-S^{\circ}(0)}{R}$ & $\frac{H^{\circ}(T)-H^{\circ}(0)}{R \mathrm{~K}}$ & $\frac{-\left\{G^{\circ}(T)-H^{\circ}(0)\right\}}{R T}$ \\
\hline 15 & 0.325 & 1.021 & 3.126 & 0.813 \\
\hline 20 & 0.403 & 1.123 & 4.913 & 0.877 \\
\hline 25 & 0.563 & 1.229 & 7.294 & 0.937 \\
\hline 30 & 0.793 & 1.351 & 10.660 & 0.996 \\
\hline 35 & 1.076 & 1.494 & 15.314 & 1.057 \\
\hline 40 & 1.395 & 1.658 & 21.477 & 1.121 \\
\hline 45 & 1.742 & 1.842 & 29.308 & 1.191 \\
\hline 50 & 2.112 & 2.045 & 38.936 & 1.266 \\
\hline 60 & 2.889 & 2.498 & 63.91 & 1.433 \\
\hline 70 & 3.691 & 3.003 & 96.80 & 1.621 \\
\hline 80 & 4.497 & 3.549 & 137.74 & 1.827 \\
\hline 90 & 5.284 & 4.125 & 186.70 & 2.050 \\
\hline 100 & 6.006 & 4.719 & 243.17 & 2.287 \\
\hline 110 & 6.699 & 5.324 & 306.72 & 2.536 \\
\hline 120 & 7.364 & 5.936 & 377.06 & 2.794 \\
\hline 130 & 7.992 & 6.550 & 453.87 & 3.059 \\
\hline 140 & 8.578 & 7.164 & 536.8 & 3.330 \\
\hline 150 & 9.125 & 7.775 & 625.3 & 3.606 \\
\hline 160 & 9.634 & 8.380 & 719.1 & 3.886 \\
\hline 170 & 10.110 & 8.979 & 817.9 & 4.168 \\
\hline 180 & 10.555 & 9.569 & 921.2 & 4.452 \\
\hline 190 & 10.973 & 10.151 & 1028.9 & 4.736 \\
\hline 200 & 11.364 & 10.724 & 1140.6 & 5.021 \\
\hline 210 & 11.731 & 11.288 & 1256.1 & 5.306 \\
\hline 220 & 12.075 & 11.842 & 1375.1 & 5.591 \\
\hline 230 & 12.398 & 12.386 & 1497.5 & 5.875 \\
\hline 240 & 12.702 & 12.920 & 1623.0 & 6.157 \\
\hline 250 & 12.988 & 13.444 & 1751.5 & 6.438 \\
\hline 260 & 13.257 & 13.959 & 1882.7 & 6.717 \\
\hline 270 & 13.511 & 14.464 & 2016.6 & 6.995 \\
\hline 280 & 13.750 & 14.960 & 2152.9 & 7.271 \\
\hline 290 & 13.977 & 15.45 & 2291.6 & 7.544 \\
\hline 300 & 14.194 & 15.92 & 2432.4 & 7.816 \\
\hline 310 & 14.401 & 16.39 & 2575.4 & 8.085 \\
\hline 320 & 14.600 & 16.85 & $2 / 20.4$ & 8.352 \\
\hline 330 & 14.790 & 17.31 & 2867.4 & 8.616 \\
\hline 340 & 14.970 & 17.75 & 3016.2 & 8.878 \\
\hline 350 & 15.14 & 18.19 & 3166.7 & 9.138 \\
\hline 273.15 & 13.587 & 14.621 & 2059.3 & 7.082 \\
\hline 298.15 & 14.154 & 15.84 & 2406.2 & 7.766 \\
\hline
\end{tabular}


we have approximated $\left\{S^{\circ}(15 \mathrm{~K})-S^{\circ}(0)\right\}$ and $\left\{H^{\circ}(15 \mathrm{~K})-H^{\circ}(0)\right\}$ in the following manner. The electric and magnetic susceptibility measurements of Folinsbee et al. indicate an antiferromagnetic ordering of the $\operatorname{Pr}^{3+}$ ions at $1.25 \mathrm{~K}$. The ground state of $\operatorname{Pr}(\mathrm{OH})_{3}$ is a doublet; therefore, this ordering will result in an entropy contribution of $R$ In 2. No significant cooperative magnetic-entropy contribution is anticipated above $25 \mathrm{~K}$. Below $25 \mathrm{~K}$ the lattice contribution can be approximated by the method described in this paper while the Schottky contribution can be calculated using the reported Stark levels. The results for the lowest lying Stark levels at 6 and $77 \mathrm{~K}$ are depicted in figure 2 . The cooperative magnetic entropy and enthalpy increments at $25 \mathrm{~K}$ were taken as $(R n \ln 2)$ and $1.25 R \ln 2)$ respectively. By summing the lattice, Schottky, and cooperative magnetic contributions, the thermodynamic functions were estimated at $25 \mathrm{~K}$. Values below $25 \mathrm{~K}$ were obtained by subtracting the calorimetrically obtained increments from the values deduced for $25 \mathrm{~K}$.

\section{The Schottky Contribution}

Resolution of the excess electronic (Schottky) heat capacity requires some basis for interpolation of the lattice heat capacity along the lanthanide series between end members. The Latimer scheme for the estimation of entropies bases the cationic contribution essentially on mass: ${ }^{(59)}$

$$
S^{\circ}(298.15 \mathrm{~K})=(3 / 2) R \ln \left(M_{\mathrm{c}} / \mathrm{g} \mathrm{mol}^{-1}\right)-3.9 \mathrm{~J} \mathrm{~K}^{-1} \mathrm{~mol}^{-1} \text {, }
$$

(slightly revised in 1951$)^{(60)}$ where $M_{\mathrm{e}}$ is the molar mass of the cation and $S^{\circ}$ is its entropy contribution. However, Debye theory leads to the well-known dependence of the characteristic temperature $\Theta_{\mathrm{D}}$ on molar mass $M$ and on molar volume $V$ :

$$
\Theta_{\mathrm{D}} \propto M^{-1 / 2} V^{-1 / 3} \text {. }
$$

Correlation of the cationic entropy contributions for compounds containing the $3-, 4-, 5-$, and $6-\mathrm{d}$ elements, ${ }^{(61,62)}$ the $4-\mathrm{f}$ elements, ${ }^{(4,63)}$ and for the mineralogically relevant silicates, ${ }^{(64,65)}$ suggest alternative approaches. We consider that, for the present, an adequate interpolation scheme for the lattice heat capacities of the lighter lanthanide trihydroxides can be formulated in terms of molar volumes; for $\operatorname{Pr}(\mathrm{OH})_{3}$ :

$$
C_{p}\left(\text { lattice, } \operatorname{Pr}(\mathrm{OH})_{3}\right\}=(1-f) C_{p}\left\{\mathrm{La}(\mathrm{OH})_{3}\right\}+f C_{p}\left\{\mathrm{Gd}(\mathrm{OH})_{3}\right\}^{*},
$$

in which $f$ may be expressed in terms of the molar volumes $V_{\mathrm{i}}$ of the isostructural lanthanide trihydroxides as

$$
f=f\left[\operatorname{Pr}(\mathrm{OH})_{3}\right\}=\left[V\left\{\operatorname{Pr}(\mathrm{OH})_{3}\right\}-V\left\{\mathrm{La}(\mathrm{OH})_{3}\right\}\right] /\left[V\left\{\mathrm{Gd}(\mathrm{OH})_{3}\right\}-V\left\{\mathrm{La}(\mathrm{OH})_{3}\right\}\right] .
$$

Here $f$ is the fractional change in molar volume for the lighter lanthanide hydroxide in question. The value of $f\left\{\operatorname{Pr}(\mathrm{OH})_{3}\right\}$ based on known lattice parameters ${ }^{(48-50,66-68)}$ is found to be 0.35 . The heat capacities of $\mathrm{Gd}(\mathrm{OH})_{3}$ and $\mathrm{La}(\mathrm{OH})_{3}$ are available elsewhere. ${ }^{(69)}$ The asterisk indicates that the heat capacity associated with the cooperative antiferromagnetic anomaly ${ }^{(70)}$ of $\mathrm{Gd}(\mathrm{OH})_{3}$ has been deleted. (When $C_{p}$ results for $\mathrm{Lu}(\mathrm{OH})_{3}$ are available the scheme can be extended. It is interesting to note that $\mathrm{Y}(\mathrm{OH})_{3}$ and $\mathrm{U}(\mathrm{OH})_{3}$ are also isostructural and will permit a more extended test of the proper mass and volume dependence. It is, however, already evident that for 
other trihydroxides ${ }^{(69)}$ as wcll as for the light trichlorides ${ }^{(4)}$ the scheme reproduces the bicusped trends in $C_{p}$ and $S$ which, as a consequence of the lanthanide contraction, are essentially perpendicular to that predicted for $S$ by the Latimer scheme.) Subtraction of the lattice contribution from the $\operatorname{Pr}(\mathrm{OH})_{3}$ total heat capacity results in the curve designated as the "calorimetric" Schottky contribution in figure 3. The solid curve in this figure was derived by using the observed energy levels and degencracics of table 1 in the general Schottky heat capacity expression:

$$
C_{V} / R=\left\{\Sigma_{\mathrm{i}} g_{\mathrm{i}}\left(\varepsilon_{\mathrm{i}} / k T\right)^{2} \exp \left(-\varepsilon_{\mathrm{i}} / k T\right)\right\} / Q-\left[\left\{\Sigma_{\mathrm{i}} g_{\mathrm{i}}\left(\varepsilon_{\mathrm{i}} / k T\right) \exp \left(-\varepsilon_{\mathrm{i}} / k T\right)\right\} / Q\right]^{2},
$$

in which $\varepsilon_{\mathrm{i}}$ represents the energies of the excited states of degeneracies $g_{\mathrm{i}} ; k, R$, and $Q$ are the Boltzmann constant, the gas constant, and the electronic partition function. As can be seen, the agreement between the "calorimetric" and "spectroscopic" Schottky contributions is good and, in fact, significantly better than previously achieved in this temperature range. The magnitude of the adjustment made between the heat capacity of $\mathrm{La}(\mathrm{OH})_{3}$ and the lattice heat capacity derived for $\operatorname{Pr}(\mathrm{OH})_{3}$ can be seen in figure 3. The additional curve indicates the Schottky contribution that result if the former is used as the approximation for the lattice contribution.

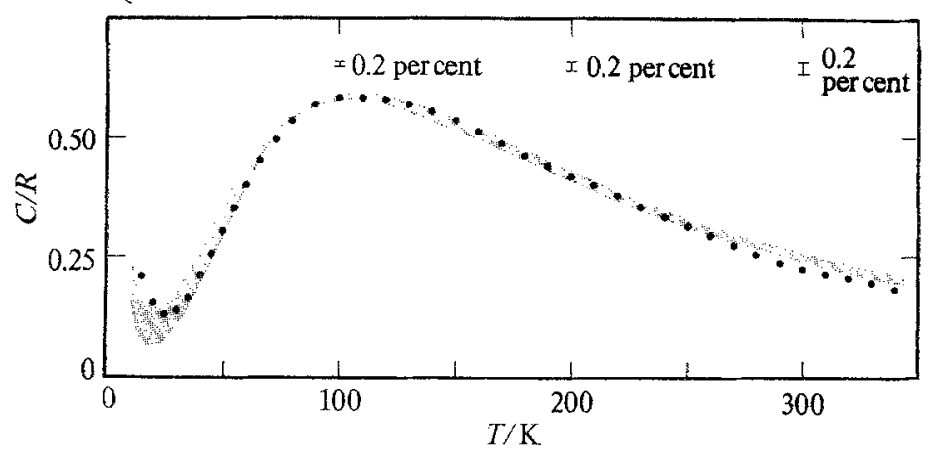

FIGURE 3. The Schottky contributions in the $\operatorname{Pr}(\mathrm{OH})_{3}$ heat capacity. The shaded area delineates the contribution calculated from the spectroscopic results (see text); the circles represent smoothed heat-capacity points resolved with the lattice heat capacity modeled in the text i.e. the "calorimetric" Schottky contribution.

In spite of the good agreement between the calorimetric and spectroscopic Schottky contributions, small discrepancies remain. Results showing deviations beyond our experimental uncertainty obtained for other trihydroxides, in particular $\mathrm{Eu}(\mathrm{OH})_{3}$ and $\mathrm{Tb}(\mathrm{OH})_{3}{ }^{(69)}$ suggest that ascribing these deviations to the approximate nature of our lattice contribution would be an oversimplification. A complicating factor is that equation (1) is rigorously correct only for a lattice of rigid point charges. Lattice expansion with increasing temperature decreases the crystalline field intensity at the cation, the ${ }^{3} \mathrm{H}_{4} J$-manifold is compressed, and, therefore, the Schottky contribution at high temperatures is decreased. At $250 \mathrm{~K}$ the calorimetric Schottky contribution trends below the spectroscopic Schottky contribution; in qualitative agreement with the effect of thermal expansion on spectroscopic results obtained at lower temperatures. Temperature-dependent spectroscopic data in the literature are insufficient to deter- 
mine whether the observed trend is quantitatively correct. A second small discrepancy is apparent near the Schottky maximum. It is clear that below $220 \mathrm{~K}$ the calorimetric Schottky contribution is shifted to slightly higher temperatures relative to the spectroscopic Schottky contribution. We believe that this could be due to differences in the vibronic states associated with the individual Stark components of the ${ }^{3} \mathrm{H}_{4} J$-manifold. Experiments are under way to elucidate the effect of these vibronic levels on the observed Schottky contribution.

\section{Summary}

In summary the thermophysical properties of $\operatorname{Pr}(\mathrm{OH})_{3}$ are seen to be the sum of the vibrational (lattice) contribution, a cooperative antiferromagnetic anomaly near $1.25 \mathrm{~K}$, a Schottky "hump" with a maximum from the lowest Stark level near $6 \mathrm{~K}$ (of which only the higher-temperature tail is apparent in our measurements), and a pronounced Schottky contribution for higher excited levels in the ${ }^{3} \mathrm{H}_{4}$-manifold (which causes the heat capacity to rise about 10 per cent above the lattice near $110 \mathrm{~K}$ ).

On the basis of a lattice heat capacity contribution interpolated on the molar-volume variation between lanthanide end-members we obtain a good resolution of the Schottky heat capacity as well as the combined measured contributions from the cooperative magnetic-anomaly and from the lower Schottky hump. The thermophysical functions were then evaluated.

Attention is called to the considerable magnitude of Schottky contributions to the heat capacity at temperatures so high that the decrease in total heat capacity associated with a Schottky "anomaly" is absent.

We appreciate the cooperation of Professor LeRoy Eyring in permitting us to incorporate the spectral results essential to the corroboration of the calorimetric Schottky contribution. We would also like to thank Dr John M. Haschke for the use of his synthetic apparatus necessary for the hydrothermal preparation of the calorimetric sample and for many helpful discussions concerning all facets of their synthesis and characterization. We also acknowledge helpful comments from H. M. Crosswhite. One of us (RDC) thanks the Exxon Corporation for a fellowship award.

\section{REFERENCES}

1. Justice, B. H.; Westrum, E. F.; Jr. J. Phys. Chem. 1963, 67, 339.

2. Westrum, E. F., Jr.; Clever, H. L.; Andrews, J. T. S.; Feick, G. Rare Earth Research III L. Eyring, ed. Gordon and Breach, New York (1966) p. 597.

3. Sommers, J. A.; Westrum, E. F., Jr. J. Chem. Thermodynamics 1976, 8, 1115.

4. Sommers, J. A.; Westrum, E. F., Jr. J. Chem. Thermodynamics 1977, 9, 1.

5. NAPS Document No. 02847. (cf. Item 47 in reference 4).

6. Meyer, H.; Smith, P. L. J. Phys. Chem. Solids 1959, 9, 285.

7. Westrum, E. F., Jr.; Justice, B. H. J. Phys. Chem. 1963, 67, 659.

8. Justice, B. H.; Westrum, E. F., Jr.; Chang, E.; Radebaugh, R. J. Phys. Chem. 1969, 73, 333. Westrum, E. F., Jr.; Justice, B. H. Rare Earth Research Conference Proceedings, 1968, 821.

9. Spedding, F. H.; Rulf, D. C.; Gerstein, B. C. J. Chem. Phys. 1972, 56, 1498.

10. Scott, P. D.; Meissner, H. E.; Crosswhite, H. M. Phys. Lett. A 1969, 28, 489.

11. Dieke, G. H. Spectra and Energy Levels of Rare Earth Ions in Crystals Interscience Publishers, New York, 1968. 
12. Gruen, D. M.; De Kock, C. W. J. Chem. Phys. 1966, 45, 455.

13. Gruen, D. M.; De Kock, C. W.; McBeth, R. L. Lanthanide/Actinide Chemistry Gould, R. F., ed., Am. Chem. Soc., Advances in Chemistry Series N71 1967, 102.

14. Wells, J. C.; Gruber, J. B.; Lewis, M. Bull. Am. Phys. Soc. 1974, 19, 1108.

15. Sayre, E. V.; Sancier, K. M.; Freed, S. J. Chem. Phys. 1955, 23, 2060.

16. Wong, E. Y.; Richman, I. J. Chem. Phys. 1962, 36, 1889.; Erratum: J. Chem. Phys. 1962, 37, 2498.

17. Wong, E. Y.; Stafsudd, O. M.; Johnston, D. R. Phys. Rev. 1963, 131, 990.

18. Hellwege, K. H.; Hess, G.; Kahle, H. G. Z. Physik. 1960, 159, 333.

19. Spedding, F. Phys. Rev. 1940, 58, 255.

20. Loh, E. Phys. Rev. 1965, 140, A1463.

21. Judd, B. R. Operator Techniques in Atomic Spectroscopy McGraw-Hill, New York, 1963.

22. Wybourne, B. G., Spectroscopic Properties of Rare Earths John Wiley, New York, 1965.

23. Bishton, S. S.; Newman, D. J. J. Phys. C 1970, 3, 1753.

24. Morrison, J. C.; Fields, P. R.; Carnall, W. T. Phys. Rev. B 1970, 2, 3526.

25. Hutchings, M. T. Solid State Physics 16, 227; Academic Press, NY, 1964.

26. Stevens, K. W. H. Proc. Phys. Soc. A 1952, 65, 209.

27. Elliott, R. J.; Stevens, K. W. H. Proc. $R$. Soc. A 1953, 218, 553; 1953, 219, 387.

28. Judd, B. R. Proc. R. Soc. A, 1955, 227, 552.

29. Gruber, J. B. USAEC Progress Reports, RLO-2012-11 (1970); RLO-2221-T6-1 (1971).

30. Rajnak, K.; Wybourne, B. G. J. Chem. Phys. 1964, 41, 565.

31. Judd, B. R. Phys. Rev. Lett. 1977, 39, 242.

32. Judd, B. R. Proceedings International Conference on Luminescence, Paris. 1978. (In press).

33. Newman, D. J. J. Phys. Chem. C: Solid State Phys. 1977, 10, 4753.

34. Judd, B. R. Proc. R. Soc. A (London) 1957, 241, 414.

35. Margolis, J. S. J. Chem. Phys. 1961, 35, 1367.

36. Rajnak, K.; Wybourne, B. G. Phys. Rev. 1963, 132, 280.

37. Wong, E. Y. J. Chem. Phys. 1963, 38, 976.

38. Wybourne, B. G. J. Chem. Phys. 1968, 48, 2596.

39. Judd, B. R.; Crosswhite, H. M.; Crosswhite, H. Phys. Rev. 1968, 169, 130.

40. Schwiesow, R. L.; Crosswhite, H. M. J. Opt. Soc. Am. 1969, 59, 592.

41. Scott, P. D.; Wolf, W. P. J. Appl. Phys. 1969, 40, 1031.

42. Cone, R. L.; Faulhaber, R. J. Chem. Phys. 1971, 55, 5198.

43. Cone, R. L. J. Chem. Phys. 1972, 57, 4893.

44. Folinsbee, J. T.; Tapster P. R.; Taylor, D. R.; Mroczkowski, S.; Wolf, W. P. Solid State Comm. 1977, 24, 499.

45. Scott, P. D.; Ph. D. Dissertation, Yale University, 1970 (unpublished)

46. Warmkessel, J. Ph. D. Dissertation, Department of Chemistry, Arizona, State University, Tempe, 1967, (unpublished).

47. Fricke, R.; Seitz, A. Z. Anorg. Chem. 1947, 254, 107.

48. Haschke, J. M.; Eyring, L. Ignor. Chem. 1971, 10, 2267.

49. Zachariasen, W. H. J. Chem. Phys. 1948, 16, 254.

50. Klevtsov, P. V.; Sheina, L. P. Izv. Akad. Nauk SSSR Neorg. Material 1965, 1, 912.

51. Gruber, J. B. (unpublished).

52. Gruber, J. B. J. Chem. Phys. 1963, 38, 946.

53. Gruber, J. B.; Satten, R. A. J. Chem. Phys. 1963, 39, 1455.

54. Westrum, E. F., Jr.; Furukawa, G. T.; McCullough, J. P. Adiabatic low-temperature calorimetry. Chap. 5 in Experimental Thermodynamics, Vol. 1. McCullough, J. P.; Scott, D. W.: editors. Butterworths: London. 1968, p. 133.

55. Stimson, H. F. J. Res. Natl. Bur. Stand. 1961, 65A, 139.

56. McCrackin, F. L.; Chang, S. S. Rev. Sci. Instrum. 1975, 46, 550.

57. Armstrong, L., Jr. J. Chem. Phys. 1969, 51, 129.

58. Justice, B. H. Thermal data fitting with orthogonal functions and combined table generation. The FITAB program, Project Report COO-1149-143, Feb. 1969. Department of Chemistry, The University of Michigan, Ann Arbor, Michigan.

59. Latimer, W. M. J. Am. Chem. Soc. 1921, 43, 818.

60. Latimer, W. M. J. Am. Chem. Soc. 1951, 73, 1480.

61. Gronvold, F., Westrum, E. F., Jr. Inorg. Chem. 1962, 1, 36.

62. Westrum, E. F., Jr. Uspekhi Khimii (in press). 
850 R. D. CHIRICO, E. F. WESTRUM, JR., J. B. GRUBER, AND J. WARMKESSEL

63. Westrum, E. F., Jr. Lanthanide/Actinide Chemistry. Gould, R. F.: ed. Am. Chem. Soc., Advances in Chemistry Series N71, 1967, 25.

64. Saxena, S. K. Science 1976, 193, 1241; Ibid. 1977, 198, 207.

65. Cantor, S. Science 1977, 198, 206.

66. Beall, G. W.; Milligan, W. O.; Wolcott, H. A. J. Inorg. Nucl. Chem. 1977, 39, 65.

67. Dillan, D. R.; Milligan, W. O.; Williams, R. J. J. Appl. Cryst. 1973, 6, 492.

68. Lance-Gomez, E. T. Ph. D. Dissertation, University of Michigan, Ann Arbor, 1976.

69. Chirico, R.; Westrum, F. F., Jr. I. Chem. Thermodynamics (to be published).

70. Skjeltorp. A. T.; Catanese C. A.; Meissner, H. E.; Wolf, W. P. Phys. Rev. B 1973, 7, 2062. 